\title{
Progress Toward Regional Measles Elimination — Worldwide, 2000-2020
}

Meredith G. Dixon, $\mathrm{MD}^{1}$; Matt Ferrari, $\mathrm{PhD}^{2}$; Sebastien Antoni, MPH${ }^{3} ; \mathrm{Xi} \mathrm{Li}, \mathrm{MD}^{1}$; Allison Portnoy, ScD ${ }^{4}$; Brian Lambert ${ }^{2}$; Sarah Hauryski ${ }^{2}$; Cynthia Hatcher, MPH ${ }^{1}$; Yoann Nedelec, MPH ${ }^{3}$; Minal Patel, MD ${ }^{1,3}$; James P. Alexander, Jr., MD ${ }^{1}$; Claudia Steulet ${ }^{3}$; Marta Gacic-Dobo, MSc ${ }^{3}$; Paul A. Rota, PhD ${ }^{5}$; Mick N. Mulders, $\mathrm{PhD}^{3}$; Anindya S. Bose, $\mathrm{MD}^{3}$; Alexander Rosewell, $\mathrm{PhD}^{3}$; Katrina Kretsinger, $\mathrm{MD}^{1}$; Natasha S. Crowcroft, MD ${ }^{3}$

In 2012, the World Health Assembly endorsed the Global Vaccine Action Plan, ${ }^{*}$ with the objective of eliminating measles $^{\dagger}$ in five of the six World Health Organization (WHO) regions by 2020 (1). The Immunization Agenda 2021-2030 $\left(\right.$ IA2030 ${ }^{\S}$ uses measles incidence as an indicator of the strength of immunization systems. The Measles-Rubella Strategic Framework 2021-2030 and the Measles Outbreaks Strategic Response Plan 2021-2023** are aligned with the IA2030 and highlight robust measles surveillance systems to document immunity gaps, identify root causes of undervaccination, and develop locally tailored solutions to ensure administration of 2 doses of measles-containing vaccine (MCV) to all children. This report describes progress toward World Health Assembly

\footnotetext{
* The Global Vaccine Action Plan is the implementation plan of the Decade of Vaccines, a collaboration between WHO; UNICEF; the Bill and Melinda Gates Foundation; the National Institute of Allergy and Infectious Diseases; the African Leaders Malaria Alliance; Gavi, the Vaccine Alliance; and others to extend the full benefit of immunization to all persons by 2020 and beyond. In addition to 2015 targets, it also set a target for measles and rubella elimination in five of the six WHO regions by 2020. https://www.who.int/teams/immunizationvaccines-and-biologicals/strategies/global-vaccine-action-plan

$\dagger$ Measles elimination is defined as the absence of endemic measles virus transmission in a region or other defined geographic area for $\geq 12$ months in the presence of a high-quality surveillance system that meets targets of key performance indicators.

$\$$ Immunization Agenda 2030 is the global vision and strategy to extend the benefits of vaccines to everyone, everywhere, developed by immunization stakeholders and endorsed by the World Health Assembly in 2020. https:// www.who.int/teams/immunization-vaccines-and-biologicals/strategies/ia2030

5 The Measles and Rubella Strategic Framework 2021-2030 aims to provide high-level guidance for developing regional and national strategies and operational plans. It was developed through a broad consultative process that generated feedback on achievements and major shortfalls in measles and rubella control over the past decade and defined strategic pivots and focus areas for the next decade. It is meant to serve as a disease-specific strategy under the IA2030 structure, and it aligns with other important strategy documents, including WHO's Thirteenth General Programme of Work 2019-2023; the UNICEF Immunization Roadmap 2018-2030; and Gavi, the Vaccine Alliance's 20212025 strategy. The Measles and Rubella Strategic Framework 2021-2030 envisions "a world free from measles and rubella." https://www.who.int/ publications/i/item/measles-and-rubella-strategic-framework-2021-2030
}

milestones and measles elimination objectives during 2000 2020 and updates a previous report (2). During 2000-2010, estimated MCV first dose (MCV1) coverage increased globally from $72 \%$ to $84 \%$, peaked at $86 \%$ in 2019 , but declined to $84 \%$ in 2020 during the COVID-19 pandemic. All countries conducted measles surveillance, although fewer than one third

\footnotetext{
** The Measles Outbreaks Strategic Response Plan 2021-2023 envisions a world in which all countries are equipped with robust measles outbreak prevention, preparedness, and response systems and contains four objectives: 1) improved coordination mechanisms for measles outbreak preparedness and response; 2) expanded vaccination efforts in vulnerable communities through resource mobilization for risk-based national plans in countries that are not eligible for Gavi support; 3) enhanced national capacity for outbreak preparedness in priority countries (e.g., planning, detection, readiness for investigation, and response), including robust surveillance; and 4) improved timeliness and effectiveness of investigation and response to measles outbreaks, including detection, root cause analysis to identify programmatic gaps to prevent future outbreaks, after action reviews and recovery. https://apps.who.int/iris/handle/10665/340657
}

\section{INSIDE}

1570 HIV Prevention Program Eligibility Among Adolescent Girls and Young Women — Namibia, 2019

1575 Influenza Vaccinations During the COVID-19 Pandemic - 11 U.S. Jurisdictions, SeptemberDecember 2020

1579 The Advisory Committee on Immunization Practices' Interim Recommendation for Use of Pfizer-BioNTech COVID-19 Vaccine in Children Aged 5-11 Years — United States, November 2021

1584 Notes from the Field: Childhood Lead Poisoning Associated with Turmeric Spices — Las Vegas, 2019

1586 QuickStats

Continuing Education examination available at https://www.cdc.gov/mmwr/mmwr_continuingEducation.html

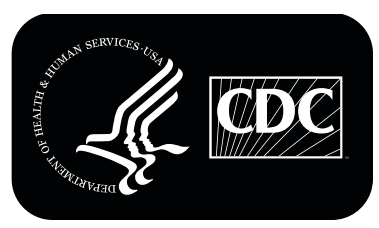

U.S. Department of Health and Human Services Centers for Disease Control and Prevention 
achieved the sensitivity indicator target of $\geq 2$ discarded ${ }^{\dagger \dagger}$ cases per 100,000 population in 2020. Annual reported measles incidence decreased $88 \%$ during 2000-2016, from 145 to 18 cases per 1 million population, rebounded to 120 in 2019 , before falling to 22 in 2020. During 2000-2020, the annual number of estimated measles deaths decreased $94 \%$, from 1,072,800 to 60,700 , averting an estimated 31.7 million measles deaths. To achieve regional measles elimination targets, enhanced efforts are needed to reach all children with $2 \mathrm{MCV}$ doses, implement robust surveillance, and identify and close immunity gaps.

\section{Immunization Activities}

WHO and UNICEF estimate immunization coverage using data from administrative records (calculated by dividing the number of vaccine doses administered by the estimated target population, reported annually), country estimates, and vaccination coverage surveys to estimate MCV1 and second dose $\mathrm{MCV}$ (MCV2) coverage through routine immunization (i.e., not mass campaigns). ${ }^{\$ S}$ During 2000-2010, estimated MCV1 coverage worldwide increased from $72 \%$ to $84 \%$. However, coverage stagnated at $84 \%-85 \%$ since 2010 , peaked at $86 \%$ in 2019 , and declined to $84 \%$ in 2020 . Regional variation exists;

\footnotetext{
$\dagger^{\dagger}$ A discarded case is defined as a suspected case that has been investigated and determined to be neither measles nor rubella using 1) laboratory testing in a proficient laboratory or 2) epidemiologic linkage to a laboratory-confirmed outbreak of a communicable disease that is not measles or rubella. The discarded case rate is used to measure the sensitivity of measles surveillance.
}

however, five of the six WHO regions reported a decline in MCV1 coverage between 2019 and 2020 (Table 1).

Among 194 WHO member states, 75 (39\%) achieved $\geq 90 \%$ MCV1 coverage in 2020, a 13\% decrease from $86(45 \%)$ countries in 2000, and a $37 \%$ decrease from $119(61 \%)$ countries in 2019. In 2020, 22.3 million infants did not receive MCV1 through routine immunization services, an increase of three million (16\%) from 2019. The 10 countries with the highest numbers of infants not receiving MCV1 were Nigeria (3.3 million), India (2.6 million), the Democratic Republic of the Congo (1.5 million), Ethiopia (1.4 million), Indonesia (1.1 million), Pakistan (1.0 million), Angola (0.7 million), the Philippines (0.6 million), Brazil (0.6 million), and Afghanistan (0.4 million); accounting for nearly two thirds (59\%) of the global total. Estimated global MCV2 coverage nearly quadrupled from $18 \%$ in 2000 to $71 \%$ in 2019 , then declined to $70 \%$ in 2020 . The number of countries offering MCV2 increased 88\%, from 95 (50\%) in 2000 to 179 (92\%) in 2020. Two countries (Madagascar and Nigeria) introduced MCV2 in 2020.

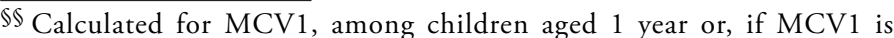
given at age $\geq 1$ year, among children aged 24 months. Calculated for MCV2 among children at the recommended age for administration of MCV2, per the national immunization schedule. WHO/UNICEF estimates of national immunization coverage are available at https://www. who.int/teams/immunization-vaccines-and-biologicals/immunizationanalysis-and-insights/global-monitoring/immunization-coverage/ who-unicef-estimates-of-national-immunization-coverage.
}

The MMWR series of publications is published by the Center for Surveillance, Epidemiology, and Laboratory Services, Centers for Disease Control and Prevention (CDC), U.S. Department of Health and Human Services, Atlanta, GA 30329-4027.

Suggested citation: [Author names; first three, then et al., if more than six.] [Report title]. MMWR Morb Mortal Wkly Rep 2021;70:[inclusive page numbers].

\section{Centers for Disease Control and Prevention Rochelle P. Walensky, MD, MPH, Director \\ Debra Houry, MD, MPH, Acting Principal Deputy Director \\ Daniel B. Jernigan, MD, MPH, Deputy Director for Public Health Science and Surveillance \\ Rebecca Bunnell, PhD, MEd, Director, Office of Science \\ Jennifer Layden, MD, PhD, Deputy Director, Office of Science \\ Michael F. Iademarco, MD, MPH, Director, Center for Surveillance, Epidemiology, and Laboratory Services}

MMWR Editorial and Production Staff (Weekly)

$$
\begin{gathered}
\text { Charlotte K. Kent, PhD, MPH, Editor in Chief } \\
\text { Jacqueline Gindler, MD, Editor } \\
\text { Brian A. King, PhD, MPH, Guest Science Editor } \\
\text { Paul Z. Siegel, MD, MPH, Associate Editor } \\
\text { Mary Dott, MD, MPH, Online Editor } \\
\text { Terisa F. Rutledge, Managing Editor } \\
\text { Teresa M. Hood, MS, Lead Technical Writer-Editor } \\
\text { Leigh Berdon, Glenn Damon, Soumya Dunworth, PhD, } \\
\text { Tiana Garrett-Cherry, PhD, MPH, Srila Sen, MA, } \\
\text { Stacy Simon, MA, Morgan Thompson, } \\
\text { Technical Writer-Editors }
\end{gathered}
$$

Matthew L. Boulton, MD, MPH

Carolyn Brooks, ScD, MA

Jay C. Butler, MD

Virginia A. Caine, MD

Jonathan E. Fielding, MD, MPH, MBA

David W. Fleming, MD

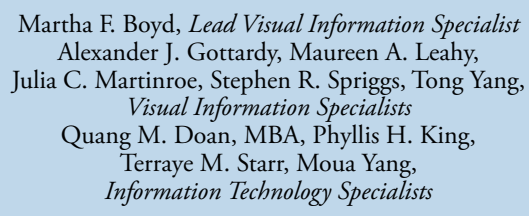

Martha F. Boyd, Lead Visual Information Specialist Alexander J. Gottardy, Maureen A. Leahy,

Julia C. Martinroe, Stephen R. Spriggs, Tong Yang, Visual Information Specialists

Quang M. Doan, MBA, Phyllis H. King,

Terraye M. Starr, Moua Yang,

Information Technology Specialists

Ian Branam, MA,

Acting Lead Health Communication Specialist Shelton Bartley, MPH, Leslie Hamlin,

Lowery Johnson, Amanda Ray,

Health Communication Specialists Will Yang, MA,

Visual Information Specialist

\section{MMWR Editorial Board}

Timothy F. Jones, MD, Chairman

William E. Halperin, MD, DrPH, MPH

Jewel Mullen, MD, MPH, MPA

Jeff Niederdeppe, $\mathrm{PhD}$

Celeste Philip, MD, MPH

Patricia Quinlisk, MD, MPH

Patrick L. Remington, MD, MPH
Carlos Roig, MS, MA William Schaffner, MD

Nathaniel Smith, MD, MPH

Morgan Bobb Swanson, BS

Abbigail Tumpey, MPH 
TABLE 1. Estimates of coverage with the first and second doses of measles-containing vaccine administered through routine immunization services, reported measles cases, and incidence, by World Health Organization region - worldwide, 2000, 2010, 2016, 2019, and 2020

\begin{tabular}{|c|c|c|c|c|c|c|}
\hline \multirow[b]{2}{*}{$\begin{array}{l}\text { WHO region/Year } \\
\text { (no. of countries in region) }\end{array}$} & \multicolumn{4}{|c|}{$\%$} & \multirow[b]{2}{*}{$\begin{array}{l}\text { No. of reported } \\
\text { measles cases } \\
\text { (\% of total cases) }\end{array}$} & \multirow[b]{2}{*}{$\begin{array}{l}\text { Measles incidence } \\
\text { per } 1 \text { million } \\
\text { population } \$ \text {, }\end{array}$} \\
\hline & $\begin{array}{l}\text { MCV1* } \\
\text { coverage }\end{array}$ & $\begin{array}{c}\text { Countries with } \geq 90 \% \\
\text { MCV1 coverage }\end{array}$ & $\begin{array}{l}\text { MCV2* }^{*} \\
\text { coverage }\end{array}$ & $\begin{array}{c}\text { Reporting countries } \\
\text { with }<5 \text { measles } \\
\text { cases per } 1 \text { million } \\
\text { population } \$\end{array}$ & & \\
\hline \multicolumn{7}{|l|}{ African } \\
\hline $2000(46)$ & 53 & 9 & 5 & 8 & $520,102(60.9)$ & 842 \\
\hline $2010(46)$ & 73 & 37 & 4 & 30 & $199,174(57.9)$ & 235 \\
\hline $2016(47)$ & 69 & 34 & 22 & 51 & $36,269(27.4)$ & 37 \\
\hline 2019 (47) & 70 & 30 & 33 & 34 & 618,595 (70.9) & 567 \\
\hline $2020(47)$ & 68 & 15 & 36 & 32 & $115,364(77.0)$ & 108 \\
\hline \multicolumn{7}{|l|}{ Americas } \\
\hline 2000 (35) & 93 & 63 & 65 & 89 & $1,754(0.2)$ & 2 \\
\hline 2010 (35) & 93 & 74 & 67 & 100 & $247(0.1)$ & 0.3 \\
\hline $2016(35)$ & 92 & 66 & 80 & 100 & $97(0.1)$ & 0.1 \\
\hline 2019 (35) & 87 & 69 & 72 & 91 & $21,971(2.5)$ & 32 \\
\hline $2020(35)$ & 85 & 37 & 73 & 100 & $1,548(1.0)$ & 2 \\
\hline \multicolumn{7}{|l|}{ Eastern Mediterranean } \\
\hline $2000(21)$ & 71 & 57 & 28 & 17 & $38,592(4.5)$ & 90 \\
\hline $2010(21)$ & 77 & 62 & 52 & 40 & $10,072(2.9)$ & 17 \\
\hline $2016(21)$ & 82 & 57 & 74 & 55 & 6,275 (4.7) & 10 \\
\hline $2019(21)$ & 84 & 52 & 75 & 42 & $18,458(2.1)$ & 27 \\
\hline $2020(21)$ & 83 & 33 & 76 & 64 & $6,122(4.1)$ & 10 \\
\hline \multicolumn{7}{|l|}{ European } \\
\hline $2000(52)$ & 91 & 62 & 48 & 45 & $37,421(4.4)$ & 50 \\
\hline $2010(53)$ & 93 & 83 & 80 & 69 & $30,625(8.9)$ & 34 \\
\hline $2016(53)$ & 93 & 81 & 88 & 82 & $4,440(3.4)$ & 5 \\
\hline $2019(53)$ & 96 & 85 & 91 & 29 & $106,130(12.2)$ & 116 \\
\hline $2020(53)$ & 94 & 57 & 91 & 80 & $10,772(7.2)$ & 17 \\
\hline \multicolumn{7}{|l|}{ South-East Asia } \\
\hline $2000(10)$ & 63 & 30 & 3 & 0 & $78,558(9.2)$ & 51 \\
\hline $2010(11)$ & 83 & 45 & 15 & 36 & $54,228(15.8)$ & 30 \\
\hline $2016(11)$ & 89 & 64 & 75 & 27 & $27,530(20.8)$ & 14 \\
\hline 2019 (11) & 94 & 73 & 83 & 30 & $29,389(3.4)$ & 15 \\
\hline $2020(11)$ & 88 & 55 & 78 & 56 & $9,389(6.3)$ & 5 \\
\hline \multicolumn{7}{|l|}{ Western Pacific } \\
\hline $2000(27)$ & 85 & 48 & 2 & 30 & $177,052(20.7)$ & 104 \\
\hline 2010 (27) & 96 & 63 & 87 & 68 & $49,460(14.4)$ & 27 \\
\hline $2016(27)$ & 96 & 63 & 93 & 68 & $57,879(43.7)$ & 31 \\
\hline 2019 (27) & 95 & 67 & 93 & 46 & $78,479(9.0)$ & 41 \\
\hline $2020(27)$ & 95 & 44 & 94 & 60 & $6,601(4.4)$ & 4 \\
\hline \multicolumn{7}{|l|}{ Total } \\
\hline $2000(191)$ & 72 & 45 & 18 & 38 & $853,479(100)$ & 145 \\
\hline 2010 (193) & 84 & 63 & 42 & 60 & $343,806(100)$ & 50 \\
\hline 2016 (194) & 85 & 61 & 67 & 70 & $132,490(100)$ & 18 \\
\hline 2019 (194) & 86 & 62 & 71 & 45 & $873,022(100)$ & 120 \\
\hline 2020 (194) & 84 & 39 & 70 & 65 & $149,796(100)$ & 22 \\
\hline
\end{tabular}

Abbreviations: $M C V 1$ = first dose of measles-containing vaccine; $M C V 2$ = second dose of measles-containing vaccine; WHO = World Health Organization.

* https://www.who.int/teams/immunization-vaccines-and-biologicals/immunization-analysis-and-insights/global-monitoring/immunization-coverage/who-unicefestimates-of-national-immunization-coverage; data accessed July 6, 2021.

$\dagger$ Denominator is the number of WHO member states.

$\S \mathrm{https} / /$ immunizationdata.who.int/pages/incidence/measles.html?GROUP\%20=\%20Countries\&YEAR\%20=; data accessed July 6, 2021. Only those countries that reported data are in the numerator and denominator.

" Population data from United Nations, Department of Economic and Social Affairs, Population Division, 2020. Any country not reporting measles cases for that year was removed from both the numerator and denominator in calculating incidence. 
Approximately 36 million persons received MCV during supplementary immunization activities (SIAs) 99 in 24 countries in 2020. An additional two million persons received MCV during measles outbreak response activities. Twenty-four SIAs in 23 countries planned for 2020 were postponed because of the COVID-19 pandemic, affecting $\geq 93$ million persons (LL Ho, WHO, personal communication, November 2021).

\section{Reported Measles Incidence and Surveillance Performance}

In 2020, all 194 countries conducted measles surveillance, and $193^{* * *}(99 \%)$ had access to standardized qualitycontrolled laboratory testing through the WHO Global Measles and Rubella Laboratory Network (GMRLN). ${ }^{\dagger \dagger}$ In spite of this access, surveillance worsened in 2020: GMRLN received 122,517 specimens for measles testing in 2020, the lowest number since 2010 , and only 46 (32\%) of 144 countries that reported discarded cases achieved the sensitivity indicator target of two or more discarded cases per 100,000 population, compared with 81 (52\%) of 157 countries in 2019.

Countries report the number of incident measles cases $\$ \$ \$ \$$ to WHO and UNICEF annually, using the Joint Reporting Form. 999 During 2000-2016, the number of reported measles

\footnotetext{
99 SIAs generally are carried out using two target age ranges. An initial, nationwide catch-up SIA focuses on all children aged 9 months-14 years, with the goal of eliminating susceptibility to measles in the general population. Periodic follow-up SIAs then focus on all children born since the last SIA. Follow-up SIAs generally are conducted nationwide every 2-4 years and focus on children aged 9-59 months; their goal is to eliminate any measles susceptibility that has developed in recent birth cohorts because of low MCV coverage and to protect children who did not respond to MCV1. Data on SIAs by country are available at https://immunizationdata.who.int/ listing.html?topic $=$ \&location $=$.

*** São Tomé and Príncipe did not have access to standardized quality-controlled testing by the WHO Measles and Rubella Laboratory Network in 2020.

话 http://www.who-measles.org/Public/Web_Front/main.php; data accessed August 3, 2021.

$\$ \$ \$$ https://apps.who.int/immunization_monitoring/globalsummary/timeseries/ tsincidencemeasles.html; accessed July 6, 2020. Only countries that reported data are in both the numerator and denominator.

999 https://immunizationdata.who.int/pages/incidence/measles.html?GROUP\%20 $=\% 20$ Countries $\&$ YEAR $\% 20=$. Countries that did not report case data, by year (total number, country name), are: 2000 (25: Algeria, Austria, Belgium, Comoros, Equatorial Guinea, Fiji, Finland, Germany, Guinea-Bissau, Ireland, Libya, Mauritania, Monaco, Montenegro, North Korea, Samoa, Saudi Arabia, Seychelles, Slovenia, Solomon Islands, South Sudan, Switzerland, Timor-Leste, Tuvalu, and Yemen); 2010 (five: Federated States of Micronesia, Libya, Monaco, Nauru, and South Sudan); 2016 (15: Belgium, Cabo Verde, Cook Islands, Haiti, Italy, Kiribati, Marshall Islands, Monaco, Morocco, Mozambique, Niue, Samoa, Singapore, Tuvalu, and Vanuatu); 2019 (nine: Austria, Djibouti, Marshall Islands, Morocco, North Korea, Palau, Solomon Islands, Switzerland, and the United States); 2020 (50: Afghanistan, Albania, Algeria, Bahamas, Belgium, Bhutan, Bosnia and Herzegovina, Brazil, Cabo Verde, Cook Islands, Cyprus, Czechia, Djibouti, Federated States of Micronesia, Fiji, Gambia, Germany, Iraq, Kuwait, Kyrgyzstan, Libya, Marshall Islands, Mauritius, Monaco, Montenegro, Morocco, Namibia, Nauru, Netherlands, Niue, North Macedonia, Oman, Palau, Peru, Poland, Portugal, Korea, Moldova, Saint Kitts and Nevis, São Tomé and Príncipe, Serbia, Singapore, Solomon Islands, Tajikistan, Thailand, Tonga, Trinidad and Tobago, Turkey, Turkmenistan, and Tuvalu). Countries do not provide WHO with their reasons for not reporting case data.
}

cases decreased $84 \%$, from 853,479 (2000) to 132,490 (2016). From 2000 to 2016, annual measles incidence decreased $88 \%$, from 145 cases per million (2000) to 18 (2016), then increased $567 \%$ to 120 per million (2019) before decreasing $82 \%$ to 22 (2020) (Table 1). In 2020, 26 large and disruptive outbreaks ( $\geq 20$ cases per million) were reported across five WHO regions (Supplementary Table, https://stacks.cdc. gov/view/cdc/111172); 17 (65\%) of these outbreaks occurred in countries in the African Region (AFR).

Genotypes of viruses isolated from persons with measles were reported by $47(46 \%)$ of 102 countries reporting at least one measles case in 2020, compared with $88(62 \%)$ of 141 countries in 2019 . The number of genotypes detected per year decreased from 13 in 2002, to three in 2020, a sign of progress toward elimination. Among 1,268 reported sequences in 2020, $947(75 \%)$ were D8, $307(24 \%)$ were B3, and 14 (1\%) were D4.

\section{Measles Case and Mortality Estimates}

A previously described model for estimating measles cases and deaths (3) was updated with annual vaccination coverage data, case data, and United Nations population estimates for all countries during 2000-2020. The model was revised $(4,5)$ to incorporate alternative assumptions of correlation between routine MCV doses and SIAs and updated case-fatality ratios, enabling derivation of new global disease and mortality estimates. On the basis of updated annual data and model revisions, the estimated number of measles cases decreased $79 \%$, from 36,763,000 in 2000 to 7,549,000 in 2020; estimated annual measles deaths decreased $94 \%$, from $1,072,800$ to 60,700 (Table 2). During 2000-2020, compared with no measles vaccination, measles vaccination prevented an estimated 31.7 million deaths globally (Figure).

\section{Regional Verification of Measles Elimination}

By the end of 2020, 81 (42\%) countries had been verified by independent regional commissions as having sustained measles elimination, but no new countries had achieved elimination. No WHO region had achieved and sustained elimination, and no AFR country has yet been verified to have eliminated measles. The WHO Region of the Americas achieved verification of measles elimination in 2016; however, endemic measles transmission was reestablished in Venezuela (2016) and Brazil (2018). Since 2016, endemic transmission has been reestablished in nine other countries that had previously eliminated measles (Albania, Cambodia, Czechia, Germany, Lithuania, Mongolia, Slovakia, the United Kingdom, and Uzbekistan). 
Morbidity and Mortality Weekly Report

TABLE 2. Estimated number of measles cases and deaths, ${ }^{*}$ by World Health Organization region — worldwide, 2000 and 2020

\begin{tabular}{|c|c|c|c|c|}
\hline $\begin{array}{l}\text { WHO region/Year } \\
\text { (no. of countries } \\
\text { in region) }\end{array}$ & $\begin{array}{l}\text { Estimated no. of measles cases } \\
(95 \% \mathrm{Cl})\end{array}$ & $\begin{array}{l}\text { Estimated no. of measles deaths } \\
(95 \% \mathrm{Cl})\end{array}$ & $\begin{array}{c}\text { Estimated \% measles } \\
\text { mortality reduction, } \\
2000-2020\end{array}$ & $\begin{array}{c}\text { Cumulative no. of measles } \\
\text { deaths averted by } \\
\text { vaccination, } 2000-2020 \\
\end{array}$ \\
\hline $\begin{array}{l}\text { African } \\
2000(46) \\
2020(47)\end{array}$ & $\begin{array}{r}11,416,700(7,212,400-16,519,900) \\
1,944,700(1,227,300-3,482,200)\end{array}$ & $\begin{array}{r}647,800(429,500-919,300) \\
33,400(22,300-56,000)\end{array}$ & 95 & $16,129,100$ \\
\hline $\begin{array}{l}\text { Americas } \\
2000(35) \\
2020(35)\end{array}$ & $\begin{array}{r}8,800(4,400-35,000) \\
43,700(21,800-174,700)\end{array}$ & $\begin{array}{l}\mathrm{NA}^{\dagger} \\
\mathrm{NA}\end{array}$ & NA & 105,200 \\
\hline $\begin{array}{l}\text { Eastern Mediterrar } \\
2000(21) \\
2020(21)\end{array}$ & $\begin{array}{r}4,641,600(2,120,400-10,419,900) \\
2,043,600(1,394,300-2,944,600)\end{array}$ & $\begin{array}{r}156,400(83,400-317,500) \\
20,400(14,400-28,700)\end{array}$ & 87 & $3,274,300$ \\
\hline $\begin{array}{l}\text { European } \\
2000(52) \\
2020(53)\end{array}$ & $\begin{array}{r}813,500(592,400-1,296,000) \\
179,600(70,800-392,500)\end{array}$ & $\begin{array}{r}4,100(3,000-5,400) \\
100(0-200)\end{array}$ & 97 & 103,400 \\
\hline $\begin{array}{l}\text { South-East Asia } \\
2000(10) \\
2020(11)\end{array}$ & $\begin{array}{r}13,856,500(10,730,400-17,563,500) \\
2,552,600(1,509,300-3,902,300)\end{array}$ & $\begin{array}{r}231,400(190,500-282,000) \\
5,600(3,800-8,000)\end{array}$ & 98 & $10,487,700$ \\
\hline $\begin{array}{l}\text { Western Pacific } \\
2000(27) \\
2020(27)\end{array}$ & $\begin{array}{r}6,026,000(4,955,600-7,899,400) \\
784,900(153,700-2,173,500)\end{array}$ & $\begin{array}{r}33,100(26,700-38,200) \\
1,200(300-2,800)\end{array}$ & 96 & $1,597,700$ \\
\hline $\begin{array}{l}\text { Total } \\
2000(191) \\
2020(194)\end{array}$ & $\begin{array}{r}36,763,000(25,615,600-53,733,800) \\
7,549,000(4,377,300-13,069,700)\end{array}$ & $\begin{array}{r}1,072,800(733,100-1,562,300) \\
60,700(40,800-95,800)\end{array}$ & 94 & $31,697,500$ \\
\hline
\end{tabular}

\section{Discussion}

A substantial decrease in measles incidence and associated mortality occurred worldwide during 2000-2016, followed by a global resurgence during 2017-2019, then an apparent decline in 2020 during the COVID-19 pandemic. Despite this decline, millions more children were susceptible to measles at the end of 2020 than in 2019. MCV1 coverage decreased globally and in all but one region in 2020; 22.3 million children did not receive MCV1 through routine immunization, and at least 93 million persons did not receive MCV because of COVID-19-related postponement of measles SIAs. Measles surveillance also deteriorated in 2020: the number of specimens submitted was the lowest in over a decade, many countries did not report, and few countries (32\%) achieved the measles surveillance sensitivity indicator. Increased population susceptibility and suboptimal measles surveillance portend an immediate elevated risk for measles transmission and outbreaks, threatening the already fragile progress toward regional elimination goals.

The extent to which measles transmission declined in 2020 is unclear. Fewer reported cases might reflect lower transmission secondary to increased immunity from outbreaks during 20172019, COVID-19 mitigation measures, or both. Conversely, measles cases might have been underreported in 2020 because of reductions in health care-seeking behavior from patients, health facility availability and reporting, or overall pandemicrelated health system disruptions. Large and disruptive measles outbreaks in 2020, however, suggest that measles transmission was underreported. Robust case-based measles surveillance systems enable countries to detect and respond promptly to measles cases and outbreaks. Expanded virologic surveillance can better monitor local patterns of transmission, particularly in high-incidence areas like AFR. The Measles Outbreaks Strategic Response Plan 2021-2023 recommends annual risk assessments to strengthen preparedness and response, investigation of every outbreak, rapid implementation of effective interventions to stop transmission, and root cause analysis to close immunity gaps and prevent future outbreaks through tailored approaches.

Coverage of $\geq 95 \%$ with MCV1 and MCV2 is necessary to ensure and sustain high population immunity against measles. MCV1 coverage has stagnated since 2010, and the largest annual increase since 2000 in children who did not receive MCV1 was reported in 2020, representing an acute setback in progress toward measles elimination $(\sigma)$. Accelerated efforts are needed to expand MCV1 coverage among the 22.3 million unvaccinated children in 2020 and ensure immunization of future birth cohorts. Routine MCV2 immunization has been recommended since 2017 (7); timely introduction is needed in the 15 countries that have yet to introduce MCV2, including 
FIGURE. Estimated number of annual measles deaths with vaccination and without vaccination* — worldwide, 2000-2020

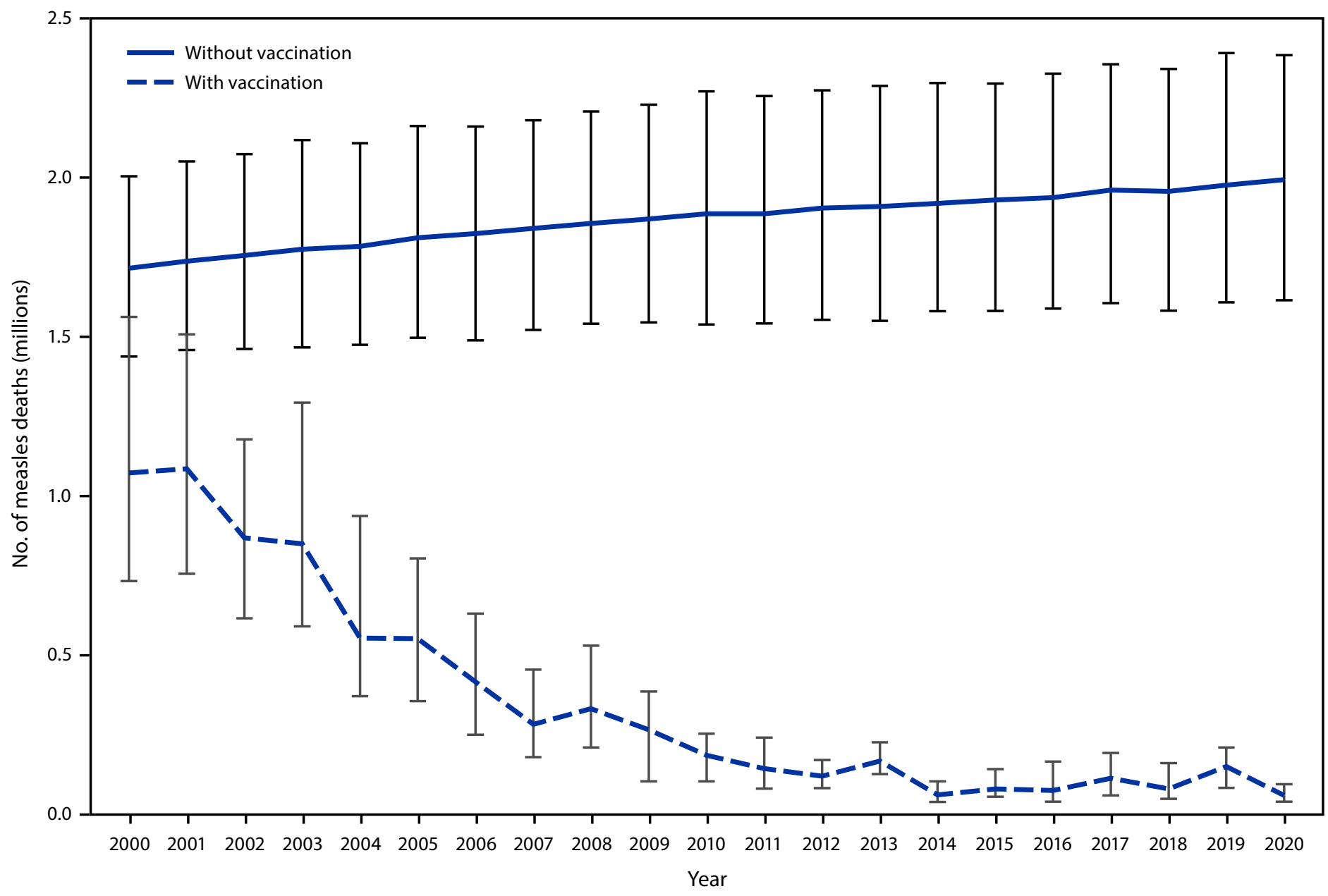

* Deaths prevented by vaccination are estimated by the area between estimated deaths with vaccination and without vaccination (total of 31.7 million deaths prevented during 2000-2020). Vertical bars represent upper and lower 95\% Cls around the point estimate.

\section{Summary}

What is already known about this topic?

All six World Health Organization (WHO) regions remain committed to measles elimination.

What is added by this report?

Annual reported measles incidence decreased globally during 2000-2016, increased in all regions during 2017-2019, then decreased in 2020. Measles surveillance, already suboptimal, worsened in 2020. Since 2000, estimated measles deaths decreased $94 \%$. Measles vaccination has prevented an estimated 31.7 million deaths worldwide. No WHO region has achieved and maintained measles elimination.

What are the implications for public health practice?

To achieve regional measles elimination targets, enhanced efforts are needed to reach all children with 2 doses of measlescontaining vaccine, implement robust surveillance, and identify and close immunity gaps.
13 of the 47 countries in AFR. The revised measles estimation model indicates that in many countries, MCV is provided through SIAs to children with access to routine services (4); instead, SIAs should aim to fill immunity gaps among persons without access to routine service delivery, including older children and adults.

The findings in this report are subject to at least three limitations. First, in 2020, 35 (18\%) countries did not report MCV1 coverage and $50(26 \%)$ did not report case data to WHO/UNICEF by the deadline. This decreased reporting precludes a complete understanding of measles epidemiology globally and regionally. Second, revisions to the measles estimation model limit comparability of the estimates in this report to those of previous years' reports. Finally, genotype data are based on a limited number of sequences, most of which do not originate from AFR, which has the highest disease incidence. The proportion of circulating genotypes might differ from those reported here. 
Progress toward measles elimination during the COVID-19 pandemic and beyond necessitates strong case-based surveillance systems to document immunity gaps and quickly identify cases and outbreaks. Outbreaks should be viewed as opportunities to identify weaknesses across the immunization system and develop tailored strategies to close immunity gaps. Together, these actions will bolster measles elimination efforts while strengthening immunization systems.

\section{Acknowledgments}

Country surveillance and immunization program staff members.

Corresponding author: Meredith G. Dixon, mgdixon@cdc.gov.

${ }^{1}$ Global Immunization Division, Center for Global Health, CDC; ${ }^{2}$ Center for Infectious Disease Dynamics, The Pennsylvania State University, University Park, Pennsylvania; ${ }^{3}$ Department of Immunization, Vaccines, and Biologicals, World Health Organization, Geneva, Switzerland; ${ }^{4}$ Center for Health Decision Science, Harvard T.H. Chan School of Public Health, Boston, Massachusetts; ${ }^{5}$ Division of Viral Diseases, National Center for Immunization and Respiratory Diseases, CDC.

All authors have completed and submitted the International Committee of Medical Journal Editors form for disclosure of potential conflicts of interest. Matt Ferrari reports grants from the Bill and Melinda Gates Foundation, the World Health Organization (WHO), and Gavi, the Vaccine Alliance, to develop measles models and travel support from WHO to attend the Strategic Advisory Group of Experts on Vaccines (SAGE) meeting in 2019 and the Measles and Rubella SAGE working group. Allison Portnoy reports grant support from The Pennsylvania State University for time and analytic contributions to this manuscript. No other potential conflicts of interest were disclosed.

\section{References}

1. World Health Organization. Global Vaccine Action Plan 2011-2020. Geneva, Switzerland: World Health Organization; 2013. https://www. who.int/teams/immunization-vaccines-and-biologicals/strategies/ global-vaccine-action-plan

2. Patel MK, Goodson JL, Alexander JP Jr, et al. Progress toward regional measles elimination-worldwide, 2000-2019. MMWR Morb Mortal Wkly Rep 2020;69:1700-5. PMID:33180759 https://doi.org/10.15585/ mmwr.mm6945a6

3. Eilertson KE, Fricks J, Ferrari MJ. Estimation and prediction for a mechanistic model of measles transmission using particle filtering and maximum likelihood estimation. Stat Med 2019;38:4146-58. PMID:31290184 https://doi.org/10.1002/sim.8290

4. Santos H, Eilertson KE, Lambert B, et al. Ensemble model estimates of the global burden of measles morbidity and mortality from 2000 to 2019: a modeling study. medRxiv [Preprint posted online October 26, 2021]. https:// www.medrxiv.org/content/10.1101/2021.08.31.21262916v3.full.pdf

5. Portnoy A, Jit M, Ferrari M, Hanson M, Brenzel L, Verguet S. Estimates of case-fatality ratios of measles in low-income and middle-income countries: a systematic review and modelling analysis. Lancet Glob Health 2019;7:e472-81. PMID:30797735 https://doi.org/10.1016/ S2214-109X(18)30537-0

6. World Health Organization. Proceedings of the Global Technical Consultation to assess the feasibility of measles eradication, 28-30 July 2010. J Infect Dis 2011;204(Suppl 1):S4-13. PMID:21666191 https:// doi.org/10.1093/infdis/jir100

7. World Health Organization. Measles vaccines: WHO position paperApril 2017. Wkly Epidemiol Rec 2017;92:205-27. English, French. PMID:28459148 